\title{
Teaching Writing Skill on Bahasa Indonesia Through Synchronous Computer Mediated Communication (SCMC): A Case of Borneo University Student on non- Language Department Learner
}

\author{
Dwi Cahyono Aji ${ }^{1 *}$ \\ ${ }^{1}$ Indonesian Language Education Department, Universitas Borneo Tarakan, Indonesia \\ *dwicahyo78@borneo.ac.id
}

\begin{abstract}
This paper aims to reveal the effectiveness of within the teaching Bahasa Indonesia writing skills. This analysis used a quasi-experimental design. The population consisted of non-linguistic students from the Borneo Tarakaan University, two classes were randomly selected as a sample, agrotechnology class A1 was used as the experimental group, while agrotechnology class A2 became the control group using the conventional approach. The data were analyzed by descriptive and inferential statistics using the computer program SPSS 20 for Windows and the results were as follows: (1) There were significant differences in writing performance among students taught with the Synchronous Computer Mediated Communication (SCMC) and conventional approach (2), the use of Synchronous Computer Mediated Communication (SCMC) was more effective than the conventional approach in teaching writing skills.
\end{abstract}

Keywords: Teaching Writing Skills, Writing Achievement, SCMC

\section{INTRODUCTION}

The lead of eduatiion in this 21 st century has been seen with a change in outlook from up close and personal instructing invironment to a more innovation and techlology-based learning invironment [1]. The fast improvement of innovation has boundlessly enhanced the substance and extent of connection. In fact, another term has seemed to mean the impact of innovation in connection - technologized cooperation (see Hutchby, 2001). Once more, this kind of collaboration can be individual or social. Phone and computer interceded human-human collaboration are two significant types of technologized social association offering different kinds of interaction that have not existed beforehand. In such interaction, the technology is viewed as an instrument to be utilized by the human to accomplish communicative goals[2].

If understudies are to be successful in school, at work, and in their own lives, they should sort out some way to write. This requires that they get adequate practice and direction recorded as a printed copy, as this marvelous mastery doesn't develop regularly. A crucial target of tutoring then is to educate understudies to use this versatile gadget enough and deftly. Various schools across the world don't achieve this objective, as a preposterous number of understudies don't get the forming capacities needed for accomplishment in the public field today. [3].

Most of our opinion on how composing is at this point taught in school settings comes from surveys getting some data about their educational practices recorded as a hard copy. (e.g., Gilbert and Graham, 2010; Tse and Hui, 2016), observational assessments expected to portray how composing is told at school (e.g., Applebee and Langer, 2011; Rietdijk, van Weijen, Jassen, van sanctum Bergh, and Rijlaarsdam, 2018), additionally, mixed strategy assessments planned to give a rich depiction of writing instruction through the two meetings (e.g., Hertzberg and Roe, 2016; McCarthy and Ro, 2011) via[3]. 
SCMC comprises of the ongoing or concurrent utilization of electronic-mediated communication technologies (for example IMs, chat, computer conferencing) to work with communications [4]. Similar investigations among SCMC and FTF conditions have given empowering proof to the utilization of innovation in the study hall, with studies recommending that text-based SCMC gives expanded saliency (Smith, 2004), stretched out promising circumstances for students to see target language highlights (Smith, 2003 ; Toyoda and Harrison, 2002), and the chance to rehash and survey past text, in this way permitting students to all the more intently center around target structures while not affecting the informative achievement of the connection (Chapelle, 2001 ) via [5].

Sauro (2011) inspected the connection among SCMC and students' syntactic, sociolinguistic, key, and discourse competences, tracking down that less than half of the included examinations looking at linguistic skill showed formative advantages. In spite of the fact that Sauro talks about essential exploration zeroed in on association-specifically exchange and criticism - the job of these interactional components isn't analyzed in a quantitative, efficient way, giving just restricted proof to the adequacy of cooperation in SCMC across different exact studies[5].

The SCMC environment has been perceived to be an incredible equalizer, due to its capacity to bring about an all the more uniformly dispersed measure of investment (for example estimated in number of words) among interactants than vis-à-vis conversations, for instance (Warschauer, 1996). Such valuable discoveries persuaded the examination focal point of the current review, which explores the collaborations of 46 third-semester students of German in two diverse composing conditions (PC intervened correspondence and gathering diaries) to figure out what kinds of social jobs students embraced in each, and regardless of whether SCMC (all students are signed on simul-taneously) might offer freedoms for fostering a bigger assortment of interactional personae-essential for exploring a bigger collection of interactional settings both on-and disconnectedthan pencil-and-paper group journals [6].

The adequacy of utilizing of coordinated CMC in the academic environment and homerooms is the "asset accessibility," how much the technology can be assembled somewhat effectively and economically [4]. In any case, the adequacy of the explicitly in the educating and learning of writing in various settings needs further investigation. Thusly, in this flow research, the SMC was examined to know its viability in the showing composing of relate text.

Writing competence is tied in with making a successful piece out of composed work to satisfy a particular reason. For instance, when composing an engaging and connecting with story, understudies embrace an account style and explanatory moves to fulfi 11 the necessities of a specific setting (e.g., study hall practice, bring home task, or in-class assessment). When understudies know about the significance of the reason, crowd, and setting of the composition, they can utilize the accompanying essential scholastic talk abilities to accomplish successful execution [7].

Writing is a complicated action. Understanding this intricacy is the way to powerful instructing of composing. In this part, I will introduce a concise chronicled outline of different ways to deal with showing composing, including the controlled methodology, process approach, and classification approach. Fundamental to executing these methodologies is understanding the recursive idea of the creative cycle and knowing what con-stitutes able composition. To be sure, composing skill incorporates not just word decisions, sentence varieties, accentuation decisions, and other semantic instruments for attachment and soundness, yet additionally ways of organizing and foster contentions at the miniature and large scale levels. Take on a composing instructional method that unequivocally prepares understudies in the perspectives processes that are helpful for acceptable composing [7].

Customary educating or conventional instructing alludes to a showing technique including teachers and the understudies connecting in an eye to eye way in the study hall. These educators start conversations in the study hall, and spotlight only on knowing substance in course readings and notes[1].

Wright (2011) recognizes between teachercentered and student-centered learning approaches along a range of five measurements: power balance, course content capacity, instructor and understudy jobs, obligation regarding learning, and appraisal 
purposes and processes[8]. Accordingly, this worldview ought to be changed to the understudy focused way to deal with make the students more dynamic in fostering their insight and capacities. In educator focused learning, instructors accept the job of information supplier while understudies work as detached beneficiaries of data. In understudy focused learning, understudies work as co-fashioners of the educational plan and their learning surroundings by setting up learning objectives, making an intelligent cycle, and taking learning outside of the study hall (Bawl and McClaskey, 2015; Campbell and Robinson, Neelands, Hewston, and Mazzoli, 2007). The last measurement concerns appraisal; while educator guided learning inspires understudies to zero in on grades, understudy focused learning advances training as an end in itself (Wright, 2011). In particular, instructor focused learning utilizes basically summative appraisal, which tests an understudy's obtaining of information after a unit of study, while understudy focused learning incorporates developmental evaluation, which happens all through the length of a unit (Stull, Varnum, Ducette, Schiller, and Bernacki, 2011) via [8].

\section{METHODOLOGY}

This research used a Quasi-experimental design with a type of posttest-only control group. The population was all agrotechnology class (pseudonym). The sample was two classes that were established using the cluster random sampling technique. It was divided into one experimental group and one control group. It can be seen in the following Table 1.

Table 1. The sample of Research

\begin{tabular}{ccc}
\hline Class & Groups & Treatments \\
\hline Agrotechnology 1 & Experiment & \\
Agrotechnology 2 & Control & Conventional
\end{tabular}

The data were collected by utilizing tests (posttest) through composing form. The tests expected to gauge the student ability in writing of recount text and the effectiveness of the treatments. The composing tests were given to the experimenal group and the benchmark group. To acquire the scores of the sttudents' composition, the raters utilized a composing rubric.

The validity of the instruments was acquired through content validity. Subsequently, the scientist requested a specialist judgment to confirm the validity from the instruments. For the reliability was utilized in which two raters were picked to survey the scores of the students' composition, both the pretest and the posttest. Then, at that point, the scores were determined by utilizing Intraclass Relationship (ICC) in SPSS 22 for windows. ICC was separated into 5 levels: little (0.00-0.25), low (0.26-0.49), moderate $(0.50-0.69)$, great $(0.70-0.89)$, and brilliant $(0.90$ $1.00)$.

Table 2. The results of ICC

\begin{tabular}{cccc}
\hline & & ICC & Result \\
\hline POST & $\begin{array}{c}\text { Single } \\
\text { measures }\end{array}$ & .968 & Excelent \\
& $\begin{array}{c}\text { Average } \\
\text { measures }\end{array}$ & .984 & Excellent \\
\hline
\end{tabular}

In view of Table 2, the aftereffects of ICC on the posttest got high qualities (for example .968,.984) with the phenomenal connection rate. Along these lines, the high-dependability coefficient of rating showed that the consequences of each rater were predictable or solid in giving scores. Along these lines, in view of the outcomes, the raters gave the steady/solid scores in evaluating the students' composition.

\section{RESULT AND DISCUSSION}

The information were examined genuinely through desriptive statistic and inferential statictic. The decriptive analysis of the pretest and posttest results have been displayed in the statistical data in Table 3.

Table 3. The Results of Pretest and Posttest

\begin{tabular}{llccc}
\hline & Min & Max & Mean \\
\hline POST & $\begin{array}{l}\text { Agrotechnology 1 } \\
\text { (SCMC)* }\end{array}$ & 83 & 95.5 & 89.66 \\
& $\begin{array}{l}\text { Agrotechnology 2 } \\
\text { (CA)* }\end{array}$ & 65.25 & 83.25 & 74.94 \\
\hline *Note: SCMC: Synchronous Computer Mediated Communication \\
CA: Conventional Approach
\end{tabular}


Alluding to Table 3, it introduced the distinctions in the posttest scores of two groups. Subsequent to giving the treatments, the posttest scores of each group yielded very fulfilling results with the mean scores of 89.66 and 74.94 respectively. For the inferential statistic, the information were investigated through the statistical tests, they are Normality Distribution test, Homogeneity of Variance test, and T-test (Independent Samples Test) in SPSS 22 for windows where the ends were drawn at level 0.05 . They were introduced in Table 4.

Table 4. The results of the Inferential Statistics

\begin{tabular}{lllcc}
\hline & & & Sig. & Result \\
\hline Normality & Posttest & SCMC & .200 & $\mathrm{p}>0.05=$ normal \\
Distribution & & CA & .170 & $\mathrm{p}>0.05=$ normal \\
$\begin{array}{l}\text { Homogeneity } \\
\text { of Variance }\end{array}$ & Posttest & & .513 & $\begin{array}{c}\text { Sig. }> \\
\text { T-Test }\end{array}$ \\
& & & .000 & $\begin{array}{c}\text { Sig. }>0.05=\text { homogenous } \\
\text { significant } \\
\text { difference }\end{array}$ \\
\hline
\end{tabular}

Riferring to Table 4, the consequence of the normality distribution test showed that the information dissemination of the pretest and posttest for the control group and the experimental groups were normal. Then, at that point, it likewise can be reasoned that the variance of the groups were homogeneous. From there on, it is proceeded to the T-test. The consequences of T-Test showed that the sig. Value (pvalue) was less than Sig. level $(\alpha)(0.05)(0.000<0.05)$. All in all, there is there is a significant difference in the students' achievement in writing of recount text among the students taught by the SCMC approach and those taught by using the conventional approach to the Agrotechnology class.

The most common way of getting the hang of composing is centered around the students' exercises (learning process) instead of the learning item. It ought to be planned well to give the encounters and comprehension to the understudies in picking up composition. Subsequently, they role is as the constructors of significance, not as the collectors the importance. Subsequently, it needs the proper learning ways to deal with help the educator and the students during the time spent instructing and picking up composition. Hypothetically, the learning approaches like SCMC approach are two effective methodologies that can be applied in educating and picking up composition. Hence, this review expected to uncover the viability of the SCMC approach in showing composing of relate text at Agrotehnology. Taking everything into account, the utilization of the SCMC approach was more compelling than that of the conventional approach.

In this review, the analyst examined the adequacy of the SCMC Approach in the educating of composing ability at Agrotechnology class. This methodology hypothetically was accepted as the effective approach. Thusly, the following area examined the discoveries to check the speculations of the viability of the SCMC approach.

The effective learning was accomplished if $75 \%$ of students arrive at a foreordained score of least criteria of authority learning. In this review, the foreordained worth of least rules of authority learning is 75 . The results of the posttest score called attention to that more than $75 \%$ of the students from Agrotectnology 1 class had scores over the authority learning value, however from agrotechnology 2 class just $50 \%$ of the understudies got scores over 75. Consequently, it caused the difference in the means scores of two gatherings in which Agrotechnology 1 class that utilized the SCMC had the mean score of 89.66 and Agrotechnologi 2 class which utilized the customary methodology got the mean score of 74.94. It implied that the getting the hang of composing which utilized the SCMC Approach was effective, however the picking up composing which applied the customary methodology was still less effective. Then, at that point, in view of the consequence of T-Test in Table 4 , it shows that the students' accomplishment in the composition of relate texts who were educated by utilizing the SCMC approach and those instructed by utilizing the regular methodology had a huge distinction, with the mean contrast of 14.72. This was in accordance with the aftereffect of exploration which tracked down that the SCMC and the conventional approach had the critical contrast, with the mean distinction of 11.97. Thusly, the utilization of the SMC Approach was more compelling than that of the conventional approach in showing composing of relate texts.

In this review, at first the class circumstance was exceptionally boisterous, the understudies were latent students, and the educator couldn't handle them well. They even couldn't make a describe text and failed to really see what the relate text is. In any case, in the wake of applying the SCMC Approach for certain 
exercises, they were dynamic, had common communication among them, and could create a relate text. The understudies additionally took an interest genuinely and intellectually in fostering the information. Also, the SCMC approach could advance the understudies' qualities, offered their viewpoints, gained good accomplishments, and got the opportunity to prepare their composing capacity. Subsequently, in this review, one might say that the utilization of the logical methodology is more powerful than that of the ordinary methodology. Albeit the analyst had prepared the instructor, the educator was as yet anxious and looked off-kilter. Ultimately, in the main gathering, the SCMC Approach was not completely executed by the instructor in light of the fact that the educator still unwittingly blended the means of the SCMC Way to deal with the customary methodology. This was demonstrated by the consequence of educator's meeting where the instructor said that it was hard for him to see each progression in the techniques of the SCMC approach. Nonetheless, at resulting gatherings, the educator started to comprehend the phases of the SCMC approach and completely applied it during the most common way of instructing and getting the hang of composing. Subsequently, the SCMC can advance the instructor's inspiration.

Dissimilar to the SCMC approach, the conventional approach was less compelling to show the composition of describe texts. This approch didn't have specific strides in its execution. Practically speaking, the instructor just utilized the course books and notes. It implies that the conventional methodology gives understudies the insignificant action where the understudies just sit and pay attention to the instructor. Truth be told, the students need to rehearse as opposed to sit and pay attention to the instructor and they additionally need spaces for their own. The positive side of the conventional approach lies on the educator who can altogether control the class and exercises in systematic design. This assertion was interestingly, with the truth of this review in light of the fact that the understudies were exceptionally uproarious and the class circumstance was hard to oversee by the instructor. Consequently, the conventional approach was a wasteful way to deal with take care of the issues in schooling, and it was in opposition to the dynamic learning idea.
Consequently, the outcomes demonstrated that the utilization of the customary methodology was less compelling in showing composing ability contrasted with different methodologies.

\section{CONCLUSION}

This examination has investigated how the adequacy of the SCMC approach in showing composing expertise. The outcomes can be summed up as follows: (1) there is a huge distinction in the sttudents' accomplishment recorded as a hard copy of relate text among the understudies instructed by utilizing the SCMC approach and those educated by utilizing the regular way to deal with the Agrotechnology class in Universitas Borneo, and (2) the utilization of the SCMC approach was more successful than that of the conventionl approach in showing composing of describe texts.

Basically, the cycles of educating and picking up composing need an imaginative educator and dynamic students. An innovative educator without a doubt picked and utilized a decent way to deal with make understudies to be more intrigued and need to master composing. By zeroing in on the understudies or ordinarily known as the understudy focused guideline, similar to the SCMC, the students can foster their entire capacities, potential, accomplishment and conduct through significant and helpful exercises, hence their insight would be more beneficial for their life. Hence, the SMC without a doubt offers another understanding in upgrading the students' composing capacity. 


\section{AUTHORS' CONTRIBUTIONS}

Dwi Cahyono Aji contributed to data collection, data analysis, writing original draft, reviewed literature, and editing the final manuscript.

\section{ACKNOWLEDGMENTS}

This research was supported by the Indonesian language education department, Universitas Borneo Tarakan. The researcher would like to thank the lecturers and all the students who participated in this research.

\section{REFERENCES}

[1] Y. W. Li, "Transforming Conventional Teaching Classroom to Learner-Centred Teaching Classroom Using MultimediaMediated Learning Module," Int. J. Inf. Educ. Technol., vol. 6, no. 2, pp. 105-112, 2016.

[2] Y. Wang, "Synchronous language learning," Lang. Learn. Technol., vol. 8, no. 3, pp. 90121, 2004.

[3] S. Graham, "Changing How Writing Is Taught," Rev. Res. Educ., vol. 43, no. 1, pp. 277-303, 2019.

[4] B. A. Olaniran, "Applying synchronous computer-mediated communication into course design: Some considerations and practical guides," Campus-Wide Inf. Syst., vol. 23, no. 3, pp. 210-220, 2006.

[5] N. Ziegler, "Synchronous Computer-Mediated Communication and Interaction," Stud. Second Lang. Acquis., vol. 38, no. 3, pp. 553586, 2016.

[6] Z. I. Abrams, "Computer-mediated communication and group journals: Expanding the repertoire of participant roles," System, vol. 29, no. 4, pp. 489-503, 2001.

[7] Ling Cheung Yin, "Teaching writing," Teach. Lang. Ski., pp. 113-134, 2014.

[8] L. Muganga and P. Ssenkusu, "TeacherCentered vs. Student-Centered: An Examination of Student Teachers' Perceptions about Pedagogical Practices at Uganda's
Makerere University," J. Chem. Inf. Model., vol. 53, no. 9, pp. 1689-1699, 2013. 